Ege Tıp Dergisi / Ege Journal of Medicine 2019;58(1):81-83

\title{
Akraba dışı allojenik kök hücre nakli ile başarıyla tedavi edilen primer ileal miyeloid sarkom
}

\section{Primary ileal myeloid sarcoma successfully treated with unrelated allogeneic stem cell transplantation}

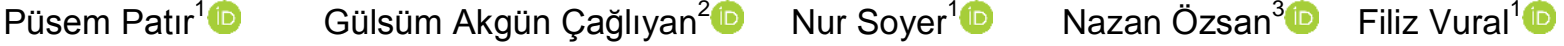 \\ ${ }^{1}$ Ege Üniversitesi Tıp Fakültesi, İç Hastalıkları Anabilim Dalı, Hematoloji Bilim Dalı, İzmir, Türkiye \\ ${ }^{2}$ Pamukkale Üniversitesi Tıp Fakültesi, İç Hastalıkları Anabilim Dalı, Hematoloji Bilim Dalı, Pamukkale, \\ Türkiye \\ ${ }^{3}$ Ege Üniversitesi Tıp Fakültesi, Tıbbi Patoloji Anabilim Dalı, İzmir, Türkiye
}

\section{Öz}

Miyeloid sarkom, granülositik sarkom veya kloroma olarak da adlandırılan olgunlaşmamış miyeloid hücre proliferasyonunun ekstramedüller tutulumudur. Miyeloid sarkom olgularının sadece $\% 6,5$ 'i gastrointestinal sistemden köken alır. Burada, hastalığın anlaşımasını arttırmak ve bireyselleştirilmiş tedaviler için bir referans sağlamak amacıyla gastrointestinal sistemden köken alan bir primer myeloid sarkom olgusu sunulmuştur.

Anahtar Sözcükler: Miyeloid sarkom, allojenik kök hücre nakli.

\begin{abstract}
Myeloid sarcoma is an extramedullary involvement of immature myeloid proliferation that is also referred to as granulocytic sarcoma or chloroma. Only $6.5 \%$ of myeloid sarcomas derive from the gastrointestinal tract. Herein, we present a case of primary myeloid sarcoma originating from the gastrointestinal tract in order to increase understanding of the disease and provide a reference for individualized therapies.
\end{abstract}

Keywords: Myeloid sarcoma, allogeneic stem cell transplantation.

\section{Giriş}

Miyeloid sarkom (MS), kemik iliği dışında bulunan miyeloid kökenli bir malign tümördür. Hava ile temas ettiğinde yeşil renk aldığı için kloroma olarak da bilinir. Akut myeloid lösemi (AML) hastalarının \%1'inden azı MS ile başvurmaktadır (1). Hem primer hem de AML, miyelodisplastik sendrom ve miyeloproliferatif hastalık ilişkili MS olgularını içeren erişkin hastaların \%6,5'i gastrointestinal sistemden tanı alır (2). Gastrointestinal kaynaklı primer MS hastalarında genellikle kemik iliği tutulumu olmaksızın karın ağrısı, bulantı, kusma, bağırsak tıkanıklığı ya da gastrointestinal kanama gibi özgül olmayan belirtiler bulunduğu için, bu hastalar kolayca yanlış teşhis edilebilir (3). Burada, hastalığın anlaşılmasını artırmak ve bireyselleştirilmiş tedaviler için bir referans sağlamak amacıyla gastrointestinal sistemden köken alan bir primer MS olgusu sunulmuştur.

\footnotetext{
Yazışma Adresi: Püsem Patır

Ege Üniversitesi Tıp Fakültesi, İç Hastalıkları Anabilim Dalı, Hematoloji Bilim Dalı İzmir, Türkiye

E-posta:pusemp@yahoo.com

Makalenin Geliş Tarihi: 05.09.2017 Kabul Tarihi: 04.12.2017
}

\section{Olgu Sunumu}

Otuz dört yaşında erkek hasta, Aralık 2012'de karın ağrısı ile hastanemizin acil servisine başvurdu. Bir yıldır ara ara karın ağrısı olan hastada ileus ile uyumlu bulgular saptandı. Bunun üzerine abdominopelvik bilgisayarlı tomografi (BT) çekildi. İleal anslar düzeyinde duvar kalınlaşması ve bu düzeyde ince bağırsaklarda ileus ile uyumlu dilatasyon izlendi. Genel Cerrahi kliniğine yatırılan hastaya laparotomi ile parsiyel ileum rezeksiyonu ve uç uca anastomoz yapıldı. İnce bağırsak ameliyat materyalinde makroskopik olarak $3 \mathrm{~cm}$ çapta izlenen tümörün histopatolojik incelemesinde bağırsak duvarını tümüyle içine alan orta boy hücrelerin oluşturduğu diffüz infiltrasyon izlendi. İmmünohistokimyasal incelemede neoplastik infiltrasyon CD34, CD68 (PG-M1), lizozim, MPO, CD117, CD38 ve bcl-2 pozitif; CD2, CD3, CD4, CD8, CD10, CD20, CD56, CD57, CD79a, CD138, MUM-1, PAX5, sitokeratin negatif saptandı. TdT ile neoplastik hücrelerde \%8 dolayında pozitiflik görüldü. Ki67 proliferasyon indeksi $\% 70$ dolayında bulundu. Kromojenik in situ hibridizasyon 
yöntemi ile çalışılan EBER incelemesinde latent EBV açısından negatif sonuç alındı. Cerrahi sınırlarda tümör yoktu. MS tanısı konulan hasta hematoloji kliniğine yönlendirildi (4).

Periferik tam kan sayımı normal sınırlardaydı: Beyaz kan hücreleri $9.840 \times 10^{9} / \mathrm{L}$, hemoglobin $14.1 \mathrm{~g} / \mathrm{dL}$ ve trombositler $281 \times 10^{9} / \mathrm{L}$. Periferik yaymada blast görülmezken, kemik iliği aspirasyon ve biyopsisinde \%23 dolayında blast izlendi. Sitarabin ve idarubicin $(7+3)$ kemoterapisi planlandı, fakat hasta tedaviyi reddetti. $\mathrm{Bu}$ nedenle takibe alındı. Mart 2013'te kontrol pozitron emisyon tomografi-BT (PET-BT) çekildi. Batın sağ alt yarısında ileal anslar arasında bağırsak duvarından kaynaklandığı düşünülen, yaklaşık $4 \times 3,5 \mathrm{~cm}$ boyutunda, artmış metabolik tutulum gösteren yumuşak doku kitlesi izlendi ve nüks lezyon olarak değerlendirildi. Kemik iliği aspirasyon ve biyopsisinde \%1-2 dolayında blastik hücre izlendi. Relaps primer miyeloid sarkom olarak değerlendirilen hastaya, 29 Mart ile 4 Nisan 2013 tarihleri arasında, sitarabin $200 \mathrm{mg} / \mathrm{m}^{2} / g u ̈ n$ ve idarubisin $12 \mathrm{mg} / \mathrm{m}^{2} / \mathrm{gün}(7+3)$ remisyon-indüksiyon kemoterapisi verildi. Aile içi tam uyumlu donörü olmayan hasta için akraba dışı donör taraması başlatıldı ve bu süreçte hastanın relaps olmaması için Mayıs ile Temmuz 2013 tarihleri arasında yüksek doz sitarabin $\left(3 \mathrm{~g} / \mathrm{m}^{2}, 12\right.$ saatte 1; 1., 3., 5. günlerde) konsolidasyon tedavisi düzenli aralıklarla uygulandı. Üçüncü kür yüksek doz sitarabin sonrası akraba dışı tam uyumlu donörü bulunan hastaya, yanıt değerlendirme amacı ile Ağustos 2013'te kontrol PET-BT çekildi ve tam metabolik yanıt izlendi. Hastaya 5 Ağustos 2014'te busulfan (3,2 mg/kg/gün, -7 ile -4. günler arasında) ve siklofosfamid $(60 \mathrm{mg} / \mathrm{kg}$, -3 ile -2. günler arasında) içeren miyeloablatif hazırlama rejimi ile 9/10 tam uyumlu akraba dışı donörden allojenik kök hücre nakli (AKHN) yapıldı. Greft ürünü $190 \mathrm{~mL}$ idi, toplam 11,31×108/kg mononükleer hücre ve 5,06x106/kg CD34 pozitif hücre hastaya infüze edildi. AKHN sonrası 12. günde hem nötrofil hem trombosit engraftmanı oldu. Graft versus host hastalığı $(\mathrm{GvHH})$ profilaksisi için kullanılan siklosporin tedavisi takipte kreatinin yüksekliği olması nedeni ile mikofenolat mofetil (1000mg/gün) ve düşük doz glukokortikoid ile değiştirildi. AKHN sonrası 28. ve 100. günde $\% 100$ tam donör kimerizmi izlendi. AKHN sonrası 2 yıl ve 5 ay sonra MS bulgusu olmadan ve kontrol altında $\mathrm{GvHH}$ ile takip edilirken, miyokard enfarktüsü nedeni ile ex oldu.

Hastadan tıbbi verilerinin yayınlanabileceğine ilişkin yazılı onam belgesi alındı.

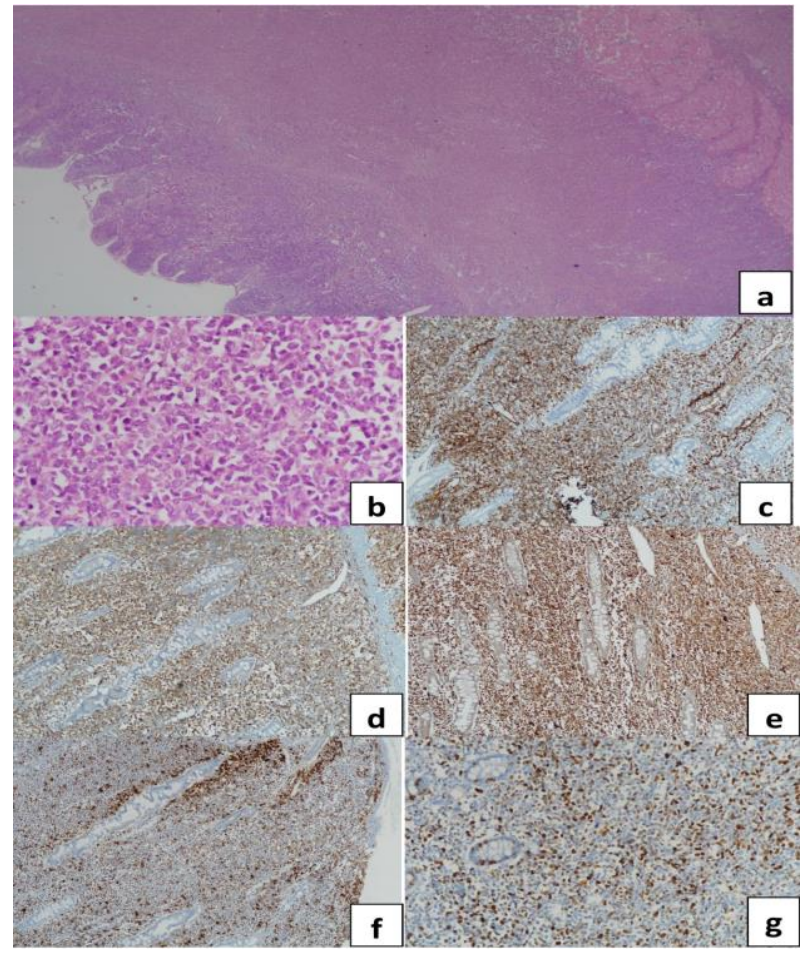

Şekil-1. a. İnce bağırsak mukozasının hemen altından başlayarak derine ilerleyen blastik morfolojide hücrelerin oluşturduğu diffüz infiltrasyon, H-Ex4. b. İnce bağırsakta blastik morfolojide hücreler, H-Ex40. c. İnce bağırsakta CD34 pozitifliği x10. d. İnce bağırsakta CD117 pozitifliği $\times 10$. e. İnce bağırsakta CD68 pozitifliği x10. f. İnce bağırsakta lizozim pozitifliği x10. g. İnce bağırsakta Ki-67 pozitifliği (\%70) x10.

\section{Tartışma}

MS başka bir hematolojik malignite ile birlikte görüldüğünde tanınması kolaydır; fakat izole veya primer MS'de, büyük bir tümör yükü durumunda bile tanı konulması daha zordur. MS şüphesinde tam kan sayımı, kemik iliği değerlendirmesi ve kromozom analizi gereklidir. MS tipik olarak, yüksek dereceli bir hematopoetik neoplazidir ve MPO veya diğer miyeloid farklılaştırıcı belirteçlerinin eşlik ettiği patolojik ve immün fenotipik özelliklere dayalı olarak teşhis edilir. MS'yi lenfomadan veya diğer tümörlerden ayırmak önemlidir. İmmünohistokimyasal incelemede en sık ifade edilen belirteç CD68/KP1 (\%100); bunu takiben diğer belirteçler MPO (\%83,6), CD117 (\%80,4), CD99 (\%54,3), CD68/PG-M1 (\%51,0), CD34 (\%43,4)'tür (2).

MS'nin prognozu son derece kötüdür. Az sayıda hastada etkili tedavilerden sonra uzun tam remisyon süreleri sağlanır. Tedavi edilmeyen primer MS, tanıdan itibaren genellikle 10-12 ay içinde AML'ye dönüşmektedir (5). Nadir durumlarda lösemiye dönüşmenin gerçekleşmediği, 16 yıldan fazla izlem süresi olan olgular da bildirilmiştir (6). Primer MS tedavisi cerrahi rezeksiyon, lokal radyoterapi ve sistemik kemoterapi seçeneklerini içerir. Bununla birlikte, cerrahi rezeksiyon ve lokal radyoterapi ile sınırlı tedaviler, MS'de AML'ye 
geçişi geciktiremez veya prognozu iyileştiremez (7). Bu da primer MS'nin sistemik tedavi gerektiren bir sistemik hastalık olduğunu gösterir ve cerrahi rezeksiyon yapılsa bile tüm primer MS'ler için sistemik kemoterapi uygulanmalıdır. Hiçbir tedavi veya takip kılavuzu olmamasına rağmen, primer $\mathrm{MS}$ tedavisinde, $\mathrm{AML}$ için kullanılan sitarabin ile kombine edilmiş antrasiklin rejimlerinin kullanımı önerilmektedir (5). AKHN, MS için etkili bir tedavi olabilir $(8,9)$. Primer MS tedavisinde AKHN uygulanması konusunda sınırlı bilgi vardır ve etkinliği hala bilinmemektedir. Bununla birlikte, aynı dönemde tedavi edilen AML hastaları ile primer MS veya AML ile birlikte eşzamanlı MS olan hastaların karakterlerini, tedavilerini ve genel sağ kalımlarını karşılaştıran retrospektif bir çalışmada, MS tanılı hastaların erken agresif AKHN tedavisinden fayda gördüğü bulunmuştur (10).

Sonuç olarak, MS, vücudun herhangi bir bölgesinde gelişebilen, miyeloid kaynaklı malign bir neoplazmdır. Gastrointestinal sistemden köken alan MS nispeten nadirdir. Primer MS'de cerrahi rezeksiyon ve radyoterapiye ek olarak yoğun sistemik kemoterapi ve AKHN yapılmalıdır.

\section{Kaynaklar}

1. Dores GM, Devesa SS, Curtis RE, Linet MS, Morton LM. Acute leukemia incidence and patient survival among children and adults in the United States, 2001-2007. Blood 2012;119(1):34-43.

2. Pileri SA, Ascani S, Cox MC, et al. Myeloid sarcoma: Clinico-pathologic, phenotypic and cytogenetic analysis of 92 adult patients. Leukemia 2007;21(2):340-50.

3. Narayan P, Murthy V, Su M, Woel R, Grossman IR, Chamberlain RS. Primary myeloid sarcoma masquerading as an obstructing duodenal carcinoma. Case Rep Hematol 2012;2012:490438.

4. Yoldaş $T$, Erol V, Demir B, Hoşcoşkun C. A rare cause of mechanical obstruction: Intestinal myeloid sarcoma. Ulus Cerrahi Derg 2013;30(3):176-8.

5. Yamauchi K, Yasuda M. Comparison in treatments of nonleukemic granulocytic sarcoma: Report of two cases and a review of 72 cases in the literature. Cancer 2002;94(6):1739-46.

6. Movassaghian M, Brunner AM, Blonquist TM, et al. Presentation and outcomes among patients with isolated myeloid sarcoma: A surveillance, epidemiology and end results database analysis. Leuk Lymphoma 2015;56(6):1698-703.

7. He J, Zhu L, Ye X, et al. Clinical characteristics and prognosis of nonleukemic myeloid sarcoma. Am J Med Sci 2014;347(6):434-8.

8. Chevallier $\mathrm{P}$, Mohty M, Lioure B, et al. Allogeneic hematopoietic stem-cell transplantation for myeloid sarcoma: A retrospective study from the SFGM-TC. J Clin Oncol 2008;26(30):4940-3.

9. Yagi T, Ishikawa J, Takahashi M, et al. Successful treatment of duodenal myeloid sarcoma with allogeneic bone marrow transplantation and additional radiotherapy. Intern Med 2012;51(7):769-72.

10. Chevallier P, Labopin M, Cornelissen J, Socié G, Rocha V, Mohty M; on behalf of the ALWP of EBMT. Allogeneic hematopoietic stem cell transplantation for isolated and leukemic myeloid sarcoma in adults: A report from the Acute Leukemia Working Party of the European group for Blood and Marrow Transplantation. Haematologica 2011;96(9):1391-4. 